\title{
OPTIMIZATION OF TERMITE IN-GROUND MONITORING STATIONS: AN EVALUATION TRIAL
}

\author{
Sónia Duarte', Adam M. Taylor ${ }^{2}$,Jeff D. Lloyd ${ }^{3}$, Marta Duarte $^{1}$, Lina Nunes ${ }^{1, \star}$
}

\begin{abstract}
Subterranean termites are serious pests of wood in service in much of the world. One of the most popular techniques for monitoring and controlling termites is the use of in-ground monitoring stations. Different cellulosic matrices were evaluated in terms of mass loss, moisture content variation and termite presence, accounting for spatial coordinates and monitoring station conditional variables, including: type of cellulosic matrix, matrix treatment and meteorological conditions, during one year in field conditions, both in Portugal and in the USA. A multivariate redundancy analysis was performed resulting in $60.4 \%$ of data variability being explained by the variables considered in this analysis. Spatial variables were responsible for the highest amount of variance observed in the response variables monitored for the termite monitoring stations, followed by the type of cellulosic matrix, from which cellulose and Hevea brasiliensis were the most influential variables. The optimization of termite in-ground monitoring stations should be performed through correct evaluation of termite feeding preferences and decay resistance, in order to choose an adequate bait matrix and a proper bait design. The termite species biology and the geographical location where control programs will be applied should also be taken into account.
\end{abstract}

Keywords: Cellulosic matrix, Hevea brasiliensis, Populus sp., Reticulitermes grassei, subterranean termites, termite monitoring stations.

\section{INTRODUCTION}

Subterranean termites have cryptic habits, living mostly in soil, and are able to become serious pests of wood in service when their foraging activities extend into man-made structures ( $\mathrm{Su}$ and Scheffrahn 2000). The use of soil termiticide barriers, which may act either by repellence or lethal contact depending on the active ingredient applied, used to be the most common curative method used by industry for termite control (Rust and Su 2012). Environmental concerns over the use of large quantities of synthetic insecticides lead to a clear decline of these methods since the 1990s (Evans and Iqbal 2015). In addition, increasing regulations of pest management has reduced the available traditional active ingredients and increased substitution by new generation chemicals (Nobre and Nunes 2007). 
The implementation of baiting as a control system for subterranean termites relies mostly on in-ground baiting stations that aim either for colony elimination or for long term termite monitoring (without the active ingredient) to prevent re-infestation by other colonies (Evans and Iqbal 2015).

In-ground monitoring stations are typically composed of a plastic holder and a cellulosic matrix (wood or other cellulose source), which is replaced by bait (active ingredient added to the cellulosic matrix or to the station) when termites are detected. This method is advantageous for termite control, since it is environmentally sound and uses small quantities of active ingredients which are insect specific (Evans and Gleeson 2006, Verma et al. 2009). Population management of termites using baiting systems implies the decrease of possible side-effects when comparing with soil termiticide barrier methods. However, research is still needed both on subterranean termite biology and on the most effective baiting system for each program.

Active ingredients used in baits must be slow acting as termites tend to avoid sites with toxicants, due to mortality or sublethal effects which cause a reduction of chemical cues sent by foraging workers (Campora and Grace 2007). Besides, termite workers may transfer toxicants to other colony members through trophallaxis, extending the effect of control to the entire colony which constitutes one of the main tenets of the termite baiting control strategies (Verma et al. 2009, Gautam and Henderson 2012).

In-ground monitoring stations can require expensive and time-consuming monitoring and replacement labour (Su and Scheffrahn 2000). Monitoring and replacement efforts may also disturb termites and result in abandonment of the bait (Gautam and Henderson 2012).

A decay resistant cellulosic matrix would allow the optimization of monitoring stations, by extending the time between visits; with the advantage of being more suitable for termite installation since it implies less disturbance from monitoring actions (Woodrow et al. 2008, Eger et al. 2014). Termite baiting control may require higher durability cellulosic matrices or baits, since control programmes may be effective only after two to fifteen months ( $\mathrm{Su}$ et al. 2002, Cabrera and Thoms 2006). Also a long-term monitoring program will require a durable cellulose matrix.

Monitoring stations matrix and baits enhancement should consider active ingredient properties (non-repellent and slow-acting), cellulosic matrix quality and quantity, termite biology (seasonal and daily patterns of activity, tunnelling behaviour and termite foragers movement pattern), and also the need for inspection and replacement (Lenz and Evans 2002, Evans and Gleeson 2006).

In continental Portugal only one species of subterranean termite is known to date (unpublished data, Nobre et al. 2006), the European subterranean termite, Reticulitermes grassei (Clément). This species is endemic to the Iberian Peninsula and southwestern France (Bankhead-Dronnet et al. 2015). In the United States, the most widely distributed termite is the Eastern subterranean termite Reticulitermes flavipes (Kollar), native to eastern US and has been introduced in Canada, South America and several European countries (Ghesini et al. 2011, Austin et al. 2012, Evans et al. 2012). Termites belonging to Reticulitermes genus forage for food away from their nest and usually rely on different food sources. The level of activity of Reticulitermes termite workers on control baits may vary within termite species, and it is also influenced by the seasonality of their foraging behaviour (Vargo 2003). Other factors such as quantity and quality of the cellulosic matrix of the control bait are also influential, as a more valuable food resource will increase the level of attraction to the termites (Lenz et al. 2009). For R. grassei there is no further information, but $R$. flavipes has already been targeted by baiting control systems (for example: Vargo 2003, Ripa et al. 2007).

The objective of this work is not directly related to the control of termites but is to study possible monitoring and bait matrices that perform better in situ for long-term monitoring and/or control plans. To this end, meteorological and geographical location variables were evaluated for impact on decay factors as mass loss and moisture content of the cellulosic matrix. 


\section{MATERIALS AND METHODS}

Different cellulosic matrices (with or without treatments) of termite monitoring stations were installed and assessed over 12 months in LNEC garden areas, in Lisbon, Portugal (N 38 $45^{\prime} 29^{\prime \prime}$, W $09^{\circ} 08^{\prime} 33^{\prime \prime}$ ), and in Nisus Corporation garden areas, in Rockford, Tennessee, USA (N 35 $51^{\prime} 59^{\prime \prime}, \mathrm{W}$ $\left.83^{\circ} 56^{\prime} 32^{\prime \prime}\right)$.

Table 1. Termite in-ground monitoring stations (cellulosic matrix and treatment applied) studied in Rockford, USA and Lisbon, Portugal.

\begin{tabular}{|c|c|c|}
\hline Location & Cellulosic matrix & Treatment \\
\hline \multirow{5}{*}{$\begin{array}{c}\text { Rockford } \\
\text { (USA) }\end{array}$} & Hevea brasiliensis & Spot treated with borate \\
\hline & & Pressure treated with borate \\
\hline & & No treatment \\
\hline & Cellulose $e^{1,2}$ & No treatment \\
\hline & Populus sp. ${ }^{1}$ & No treatment \\
\hline \multirow{5}{*}{$\begin{array}{c}\text { Lisbon } \\
\text { (Portugal) }\end{array}$} & Hevea brasiliensis & Spot treated with borate \\
\hline & & Pressure treated with borate \\
\hline & & No treatment \\
\hline & Cellulose $^{1,2}$ & No treatment \\
\hline & Populus sp. ${ }^{1}$ & No treatment \\
\hline
\end{tabular}

${ }^{1}$ Both cellulosic matrices (cellulose and Populus sp.) were together in the same plastic cage. BASF.

${ }^{2}$ Prescription Treatment ${ }^{\circledR}$ brand Advance ${ }^{\circledR}$, Whitmire Micro-Gen Research Laboratories, Inc., now

The monitoring stations installed in the field were composed of a plastic cage (Advance ${ }^{\circledR}$ ) containing different cellulosic matrices, which were never replaced during the trial (Table 1). At each location (Lisbon and Rockford) five replicates of each monitoring station were installed. 


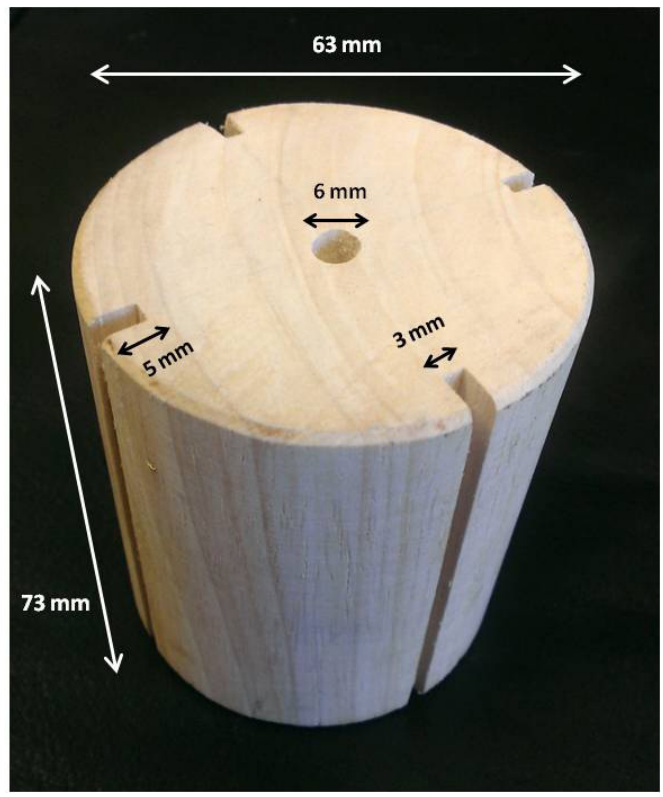

Figure 1. Hevea brasiliensis matrix photo showing the lateral and top view and the dimensions of the block. Figure not drawn to scale.

The commercially available monitoring stations, with both Populus sp. (Malpighiales: Salicaceae) and cellulose matrices together, were set up according to the company technical instructions. The Hevea brasiliensis (Willd. ex A. Juss.) Müll. Arg. (Malpighiales: Salicaceae) matrices were cut from commercial green untreated lumber in Thailand. The bait units were then dried and heat treated to meet phytosanitation requirements before transportation to Rockford, Tennessee, USA; these units are not currently commercially available. The $H$. brasiliensis matrix dimensions and aspect are stated in Figure 1; a $60 \mathrm{~mm}$ deep hole was drilled in all these samples to allow spot treatments when relevant, and four grooves were made in the block to increase the contact surface for the termites. The spot treated $H$. brasiliensis samples were treated with $4 \mathrm{ml}$ of a $20 \%$ disodium octaborate tetrahydrate (DOT) solution which was put into the hole of the samples, resulting in approximately $0.5 \%$ DOT local retention. For the pressure treated $H$. brasiliensis samples, the pressure treatment made resulted in approximately $0.45 \pm 0.02 \%$ DOT dry weight retention. The in-ground stations were set three meters apart from each other, in a series of different matrices, in garden areas without irrigation both in Rockford and Lisbon. A hole was drilled in the soil, and the monitoring stations were buried, leaving only the cap at the soil level. The cellulosic matrix performance was evaluated in terms of mass loss, moisture content, and termite presence. As the methodology for moisture content measure demands obligatory disturbance of the baits, the termite presence may have been influenced by this disturbance although it was equal with all station types. However, the main goal of this work was to evaluate the decay factors of different baiting systems and locations. Moisture content and termite presence were monitored weekly in the first month, fortnightly during the second month, monthly until the sixth month and in the end of the trial, for a total of 12 monitoring events. For moisture content (MC) measures over time, five replicates of each cellulosic matrix were weighed, oven-dried and re-weighed to obtain a starting MC value for each cellulosic matrix. All cellulosic matrices were weighed at the beginning of the trial, so that, together with the assumed starting $\mathrm{MC}$, the calculations for $\mathrm{MC}$ at each monitoring date could be carried out according to the formula (1). The termite presence was evaluated according to their presence (1) or absence (0) on the cellulosic matrix, and the final value is the sum of all presences within the 12 monitoring events. 
Total mass loss was evaluated in the end of the trials. The mass loss (\%) was obtained from the loss of the dry mass of the exposed test specimens accordingly with the following protocol. The moisture content of each type of cellulosic matrix was calculated from the initial mass of one specimen of each type of cellulosic matrix and the dry mass of that specimen after oven drying at $103^{\circ} \mathrm{C}$ for $24 \mathrm{~h}$. The moisture content was obtained according with (1):

$$
\text { Moisture Content }(M C)=\frac{W M-D M}{D M} \times 100
$$

Where WM is the initial mass, before oven drying; and DM is the dry mass, after the specimen has been oven dried at $103^{\circ} \mathrm{C}$ for $24 \mathrm{~h}$. To avoid submitting the test specimens to moisture variations, the theoretical dry mass of the test specimens exposed to the termites was also calculated (2):

$$
\text { Theoretical Dry Mass }(T D M)=S-(S \times M C)
$$

Where $\mathrm{S}$ is the initial mass of the test specimens; and MC is the moisture content previously calculated for each cellulosic matrix type. For calculating the theoretical mass loss, the test specimens were oven dried at $103^{\circ} \mathrm{C}$ for $24 \mathrm{~h}$, after exposure to the field conditions. The theoretical mass loss, which represents the amount of cellulosic matrix presumably consumed by termites, was then obtained (3):

$$
\text { Theoretical Mass Loss }(T M L)=T M D-F D M
$$

Where TDM is the theoretical dry mass previously calculated; and FDM is the final dry mass of the test specimens after oven drying at $103^{\circ} \mathrm{C}$ for $24 \mathrm{~h}$.

The meteorological data was obtained from nearby meteorological stations: in Portugal data from Weather underground (2012/03/02) for Cais do Sodré station; and from the National Weather Service for Knoxville data from National Weather Service Forecast office (2012/03/02) for Knoxville airport station. Meteorological data included the daily average temperature, average relative humidity and cumulative rain values (Figures 2 and 3 ). 
a)

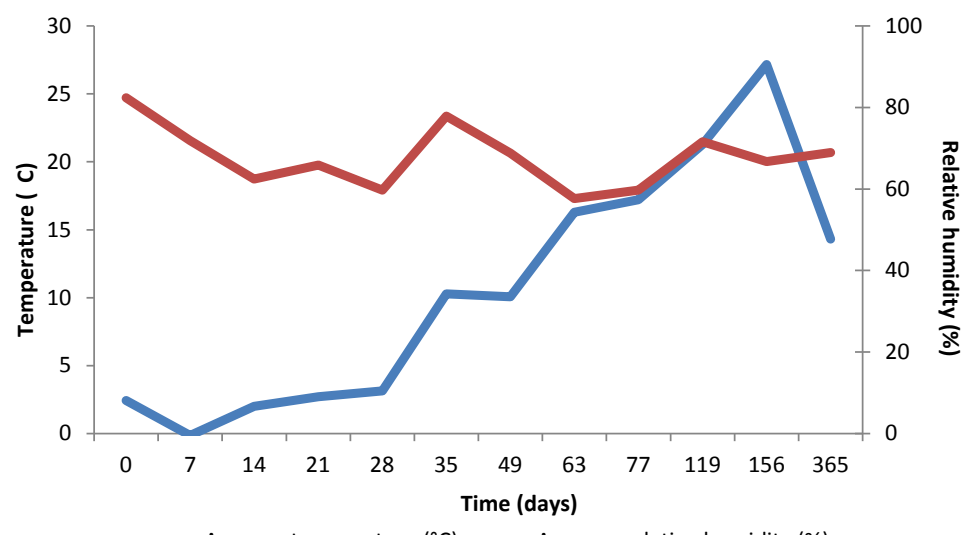

$\Longrightarrow$ Average temperature $\left({ }^{\circ} \mathrm{C}\right) \longrightarrow$ Average relative humidity (\%)

b)

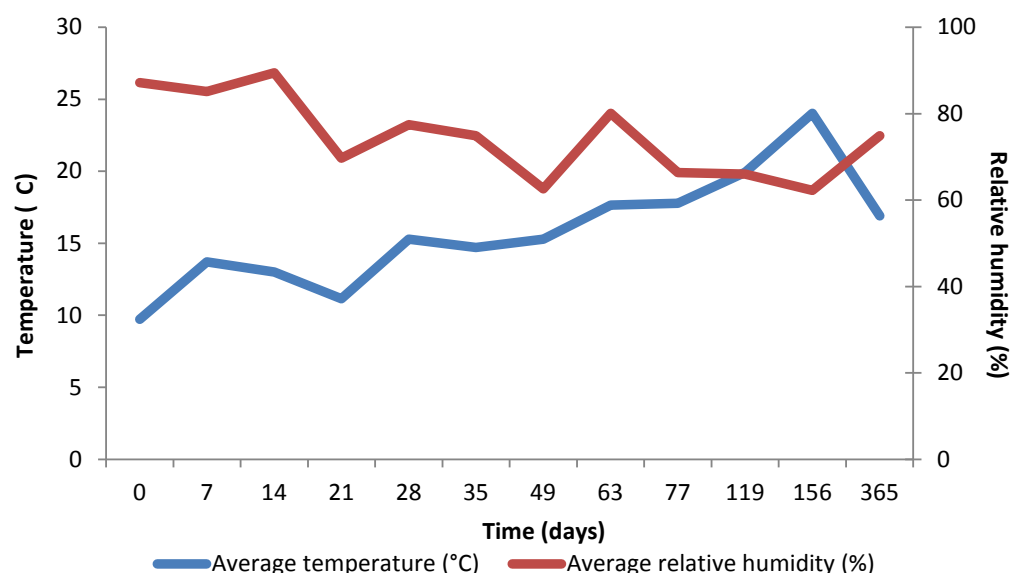

Figure 2. Average temperature $\left({ }^{\circ} \mathrm{C}\right)$ and average relative humidity $(\%)$ values during monitoring time for: a) Rockford, and b) Lisbon.

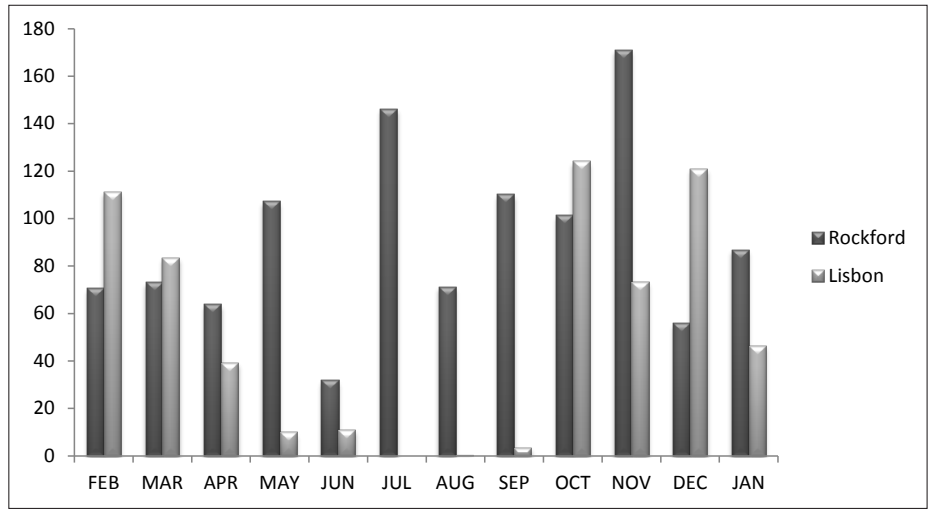

Figure 3. Cumulative monthly precipitation $(\mathrm{mm})$ in Rockford, USA and Lisbon, Portugal, during the monitoring, which occurred between February 2010 and January 2011. 
Monitoring station data, in terms of mass loss, moisture content and termite presence, as well as geographical location data, were partitioned into four matrices, in order to perform a variance partitioning analysis (which enables the allocation of the influence of each conditional variable to the effects on variables measured), namely: spatial variables (spatial coordinates - S) (1), monitoring station conditional variables (MS), including type of matrix (2), matrix treatment (3) and meteorological data (4) (Table 2). The spatial data set consisted of eight spatial variables constructed from the xy coordinates of both study areas, through their square order combinations. The coordinates were centred on their means and divided by their standard deviation. The appropriate algebraic calculation was conducted on the coordinates to create each spatial variable (Borcard et al. 1992, Grand and Cushman 2004). Matrix variables included the type of cellulosic matrix: cellulose powder or different solid wood species $-H$. brasiliensis and Populus sp. Matrix treatment variables refer to whether the cellulosic matrix was exposed to any treatment (spot treatment with borate, pressure treatment with borate or no treatment).

Statistical analysis. For each monitoring station 17 variables organized in four groups ( $\mathrm{S}$ - spatial variables; $\mathrm{M}$ - type of cellulosic matrix; $\mathrm{T}$ - cellulosic matrix treatment; and $\mathrm{E}$ - meteorological data) were analysed for their influence in the monitoring station performance criteria: mass loss, moisture content variation over time in the cellulosic matrices and termite presence or absence (Table 2). The spatial variables data set analysis allowed for the relation between monitoring stations features and the spatial coordinates, as well as a measure of the amount of variance in the monitoring station performance data that can be explained by the supplied spatial matrix (Borcard et al. 1992).

Table 2. Constitution of the four groups of variables considered for variance partitioning: Spatial variables $(\mathrm{S})$ and monitoring station conditional variables: Type of matrix $(\mathrm{M})$ matrix treatment $(\mathrm{T})$ and Meteorological data (E) recorded for termite in-ground monitoring stations located in Rockford and Lisbon, in 2010.

\begin{tabular}{|c|c|c|}
\hline Set of variables & Variable & Definition \\
\hline \multirow{8}{*}{ Spatial variables $(\mathrm{S})$} & $\mathrm{X}$ & UTM X coordinate, standardized to zero mean and unit variance \\
\hline & $\mathrm{Y}$ & UTM Y coordinate, standardized to zero mean and unit variance \\
\hline & $\mathrm{XY}$ & Product of $\mathrm{X}$ and $\mathrm{Y}$ \\
\hline & $\mathrm{X}^{2}$ & Square root of $\mathrm{X}$ \\
\hline & $\mathrm{Y}^{2}$ & Square root of $\mathrm{Y}$ \\
\hline & $X Y^{2}$ & Product of $\mathrm{X}$ and square root of $\mathrm{Y}$ \\
\hline & $\mathrm{X}^{2} \mathrm{Y}$ & Product of square root of $\mathrm{X}$ and $\mathrm{Y}$ \\
\hline & $\mathrm{X}^{2} \mathrm{Y}^{2}$ & Product of square root of $\mathrm{X}$ and square root of $\mathrm{Y}$ \\
\hline \multirow{3}{*}{ Type of matrix (M) } & Cellulose & Binary, 1 if monitoring station matrix was cellulose \\
\hline & Hevea brasiliensis & Binary, 1 if monitoring station matrix was Hevea brasiliensis \\
\hline & Populus sp. & Binary, 1 if monitoring station matrix was Populus sp. \\
\hline \multirow{3}{*}{ Matrix treatment $(\mathrm{T})$} & Spot treated with borate & Binary, 1 if monitoring station matrix was spot treated with borate \\
\hline & Pressure treated with borate & Binary, 1 if monitoring station matrix was pressure treated with borate \\
\hline & No treatment & Binary, 1 if monitoring station matrix was not subjected to any treatment \\
\hline \multirow{3}{*}{$\begin{array}{c}\text { Meteorological data } \\
\text { (E) }\end{array}$} & Temperature & Average temperature $\left({ }^{\circ} \mathrm{C}\right)$ \\
\hline & Relative humidity & Average relative humidity $(\%)$ \\
\hline & Cumulative rain & Average cumulative rain (mm) \\
\hline
\end{tabular}


Measurement of the amount of variance in monitoring station performance data (different behavior in terms of total mass loss, moisture content variation and termite presence), which may be explained by selected spatial and monitoring station conditional variables, was assessed by multivariate techniques, with CANOCO 4.5 software $(\mathrm{p}<0.05)$ (Ter Braak and Smilauer 2002). Redundancy analysis (RDA) and partial RDA, using log transformed data, were used to perform the variance partitioning, which provides a comparison of relative importance of different variables considered potentially important in structuring termite monitoring station features. Methods proposed by Borcard et al. (1992) for partition of data variance among environmental and spatial factors were adapted. Through the calculation of a series of RDAs and partial RDAs, it was possible to isolate the portions of data variance which are explained by each set of explanatory variables alone, as well as by interactions among different sets of explanatory variables (Legendre and Legendre 1998, Cushman and Wallin 2002).

\section{RESULTS AND DISCUSSION}

Reticulitermes grassei (Clément) was identified as the termite found in Lisbon. Reticulitermes flavipes (Kollar) was identified in Rockford, TN. Both species were identified by one of the authors based on the analysis of the soldier morphological characters.

Though the chosen areas of study have termite activity, the termite presence was low throughout the test period but termites were identified at least once in $40 \%$ of the stations with $H$. brasiliensis matrix, regardless of treatment. The reason for this fact may rely in the disturbance caused by cellulosic matrix handling during the moisture content monitoring. However extended periods of termite low activity on baits while attacking other food sources has been observed by other authors (Glenn and Gold 2002), reinforcing the importance of the durability of cellulosic matrices used for baiting of recruiting termite workers. On cellulose powder and Populus sp. matrices, termites were detected only once. Mass loss values were considerably higher in Lisbon, especially for $H$. brasiliensis (Table 3 ); the highest mass loss values are not always associated with termite attack, although the higher presence of termites was observed in Lisbon, and can therefore be also attributed to fungal decay (Taylor et al. 2010). 
Table 3. Total mass loss (\%) and termite presence in the different monitoring stations tested, with five replicates.

\begin{tabular}{|c|c|c|c|c|c|c|c|}
\hline & & & Rockford & & & Lisbon & \\
\hline Cellulosic matrix & Treatment & Replicates & $\begin{array}{c}\text { Mass loss } \\
(\%)\end{array}$ & $\begin{array}{c}\text { Termite } \\
\text { presence }\end{array}$ & Replicates & $\begin{array}{c}\text { Mass loss } \\
(\%)\end{array}$ & $\begin{array}{r}\text { Termite } \\
\text { presence }\end{array}$ \\
\hline \multirow{15}{*}{$\begin{array}{l}\text { Hevea } \\
\text { brasiliensis }\end{array}$} & \multirow{4}{*}{$\begin{array}{l}\text { Spot treated } \\
\text { with borate }\end{array}$} & HSB_Rl & 0,20 & 1 & HSB_Ll & 34,86 & 4 \\
\hline & & HSB_R2 & 0,15 & 0 & HSB_L2 & 29,08 & 0 \\
\hline & & HSB_R3 & 0,17 & 0 & HSB_L3 & 19,85 & 0 \\
\hline & & HSB_R4 & 0,12 & 0 & HSB_L4 & 20,17 & 0 \\
\hline & \multirow{5}{*}{$\begin{array}{l}\text { Pressure treated } \\
\text { with borate }\end{array}$} & HSB_R5 & 0,10 & 0 & HSB_L5 & 21,48 & 0 \\
\hline & & HPB_Rl & 0,19 & 0 & HPB_Ll & 32,41 & 4 \\
\hline & & HPB_R2 & 0,14 & 0 & HPB_L2 & 28,59 & 0 \\
\hline & & HPB_R3 & 0,11 & 0 & HPB_L3 & 36,16 & 0 \\
\hline & & HPB_R4 & 0,08 & 0 & HPB_L4 & 33,23 & 0 \\
\hline & \multirow{6}{*}{ No treatment } & HPB_R5 & 0,10 & 0 & HPB_L5 & 26,42 & 0 \\
\hline & & HNT_Rl & 0,24 & 0 & HNT_Ll & 23,97 & 2 \\
\hline & & HNT_R2 & 0,18 & 0 & HNT_L2 & 38,36 & 0 \\
\hline & & HNT_R3 & 0,26 & 0 & HNT_L3 & 30,08 & 0 \\
\hline & & HNT_R4 & 0,60 & 0 & HNT_L4 & 27,16 & 1 \\
\hline & & HNT_R5 & 0,19 & 0 & HNT_L5 & 16,39 & 0 \\
\hline \multirow[t]{5}{*}{ Cellulose } & \multirow[t]{5}{*}{ No treatment } & C_R1 & 0,00 & 0 & C_L1 & 0,00 & 0 \\
\hline & & C_R2 & 1,00 & 1 & C_L2 & 0,14 & 0 \\
\hline & & C_R3 & 0,02 & 0 & C_L3 & 0,00 & 0 \\
\hline & & C_R4 & 0,00 & 0 & C_L4 & 0,00 & 0 \\
\hline & & C_R5 & 0,00 & 0 & C_L5 & 0,00 & 0 \\
\hline \multirow[t]{5}{*}{ Populus sp. } & \multirow[t]{5}{*}{ No treatment } & P_R1 & 0,27 & 0 & P_L1 & 8,28 & 0 \\
\hline & & P_R2 & 1,00 & 2 & P_L2 & 11,50 & 0 \\
\hline & & P_R3 & 0,32 & 0 & P_L3 & 0,00 & 0 \\
\hline & & P_R4 & 0,43 & 0 & P_L4 & 2,77 & 0 \\
\hline & & P_R5 & 0,85 & 0 & P_L5 & 10,82 & 0 \\
\hline
\end{tabular}

The variation on the average moisture content of each monitoring station showed that the Populus sp. matrix had a less stable behavior, for both locations, in terms of moisture content, compared to the other matrices (Figure 4). All the cellulosic matrices reached a level of above $20 \%$ moisture content within two weeks, thus allowing fungal activity. 


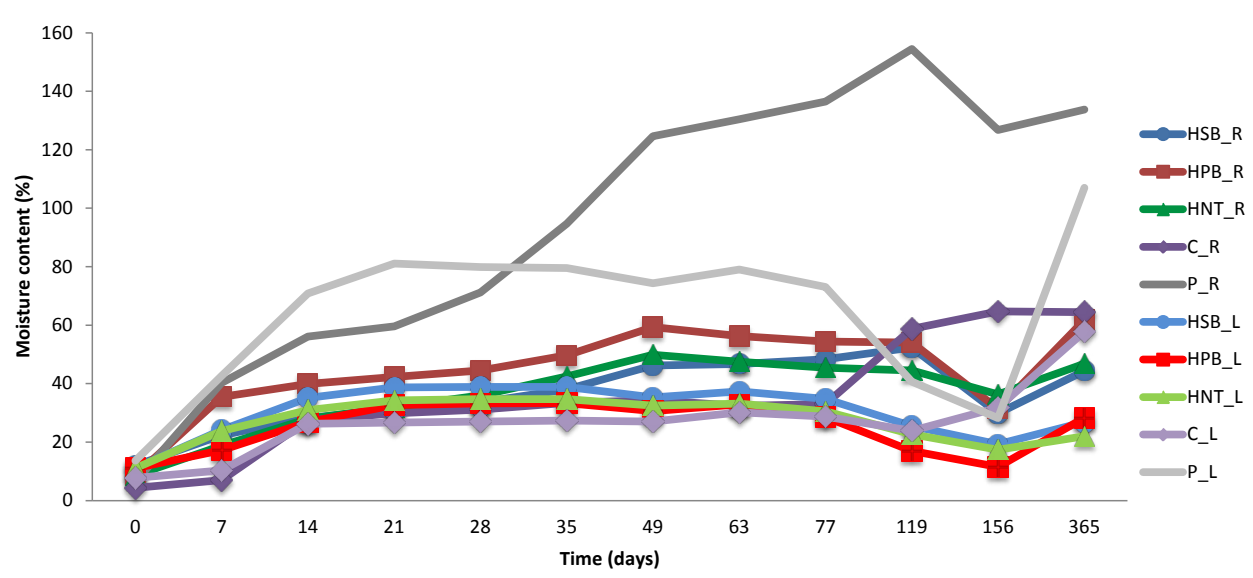

Figure 4. Moisture content (\%) variation along monitoring time for the different monitoring stations: HSB_R, H. brasiliensis spot treated with borate; HPB_R, H. brasiliensis pressure treated with borate; $\mathrm{HNT}_{-} \mathrm{R}, H$. brasiliensis not treated; C_R, cellulose powder not treated; $\mathrm{P} \_\mathrm{R}$, Populus sp. not treated, these five baits were installed in Rockford, USA; HSB_L, H. brasiliensis spot treated with borate; HPB_R, H. brasiliensis pressure treated with borate; HNT_R, H. brasiliensis not treated;

C_L, cellulose powder not treated; P_L, Populus sp. not treated, these five baits were installed in Lisbon, Portugal.

In the first partition level, which included spatial (S) and monitoring station conditional (MS) variables, the results showed that the variables explained $60.4 \%$ of monitoring station data variance (Figure 5).

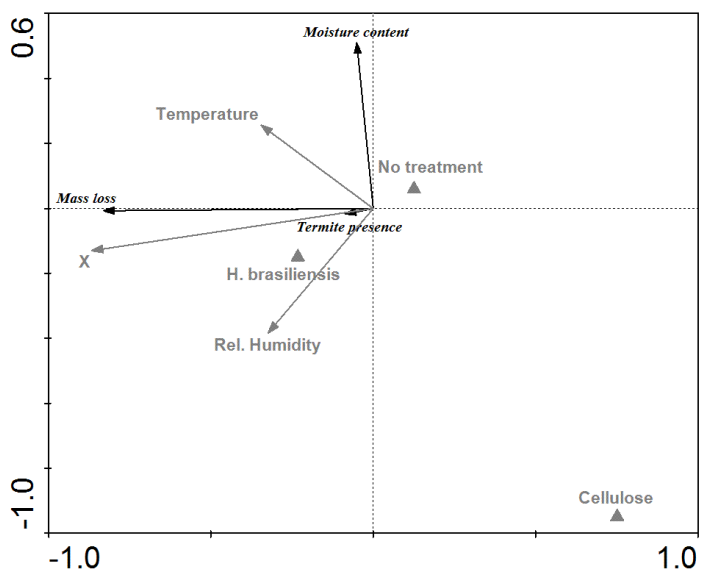

Figure 5. RDA biplot for monitoring stations decay factors and selected variables: spatial (X UTM coordinate) and monitoring station conditional data: Cellulose, $H$. brasiliensis (Type of matrix); Relative humidity, Temperature (Meteorological data); and No treatment (Matrix treatment). 
The variables which were considered to be significant $(p<0.05)$ were: UTM X coordinate $(X)$ for Spatial variables, cellulose and $H$. brasiliensis, Type of matrix variables; and Temperature and Relative humidity for Meteorological variables. The No treatment variable from Matrix treatment group, was not considered significant, but had as much variability as Temperature (Table 4).

Table 4. Variables selected from the four groups of variables analyzed after redundancy analysis (significant variables for $\mathrm{P}<0.05$ ); with the response variables: mass loss and moisture content of cellulosic matrix and termite presence in the monitoring stations.

\begin{tabular}{|llccc|}
\hline Set of variables & Selected variables & $\begin{array}{c}\text { Explained } \\
\text { variance (\%) }\end{array}$ & $\boldsymbol{r}$ & P-value \\
\hline Spatial variables (S) & $\mathrm{X}$ & 42 & 474,4 & 0,002 \\
& & & & \\
Type of matrix (M) & Cellulose & 12 & 178,9 & 0,002 \\
& Hevea brasiliensis & 5 & 83,0 & 0,002 \\
Matrix treatment (T) & No treatment & 0 & - & - \\
& & & & \\
Meteorological data (E) & Relative humidity & 1 & 10,4 & 0,002 \\
& Temperature & 0 & 4,4 & 0,012 \\
\hline
\end{tabular}

The cumulative rain variable was expected to be significant, but the fact that the garden areas were watered once a week in the hot season in Portugal may have affected the data. The residual variance $(39.6 \%)$ is the amount of variance in monitoring station features data which could not be explained by this model. The partial RDA showed that the joint effects of MS and S variables were 17.1\%; while the spatial variables alone were responsible for $24.8 \%$ of variance observed (Figure 6).

In the second partition level the distribution of the variance associated to the MS data set among the three groups of variables was of $18.5 \%$.

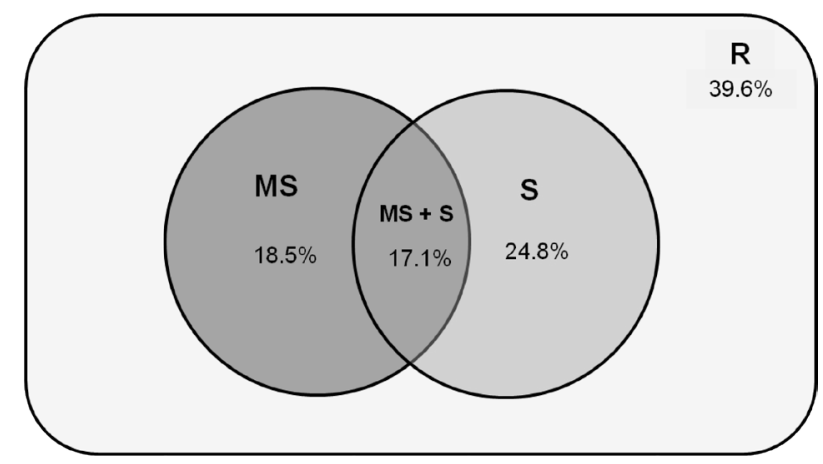

Figure 6. Percent of total variance of monitoring station data obtained, explained by monitoring station conditional data (MS), spatial variables (S) and both monitoring stations conditional data and spatial variables together $(\mathrm{MS}+\mathrm{S})$. The variance of the data which is not explained by this model is the residual variance $(\mathrm{R})$. Figure is not drawn to scale. 
Type of matrix was the most important data set (13.1\%); the joint effects of this group and Matrix treatment were also considered important (4.4\%). The Meteorological data $(0.9 \%)$ do not seem to interact with the other two groups of variables (Figure 7).

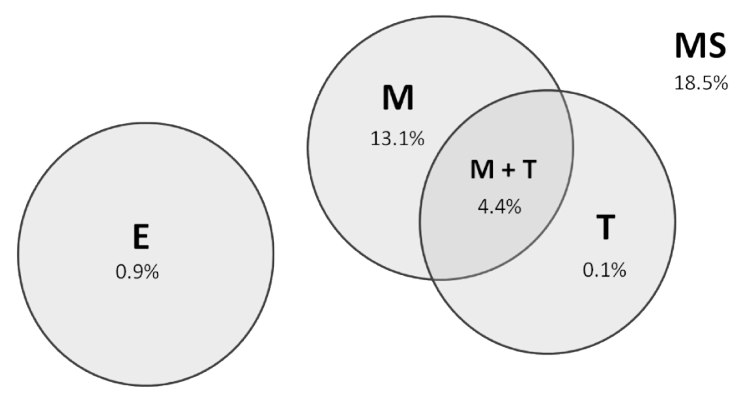

Figure 7. Diagram showing fractions for the partitioning of explained variance, by monitoring station features variables, of monitoring stations data, in Lisbon and Rockford, into four components:

(1) partial effects of Matrix (M), (2) partial effects of Monitoring stations design (D), (3) partial effects of Meteorological data (E), (4) partial joint effects of Matrix and Monitoring stations design $(\mathrm{M}+\mathrm{D})$. Figure is not drawn to scale.

Spatial variables (based on spatial coordinates), were responsible for a high amount of variance observed in termite monitoring stations response variables. Factors such as soil type or moisture level and the availability of alternative food sources may be very important for the determination of subterranean termites foraging patterns in microhabitats (Lenz et al. 2009, Cornelius and Osbrink 2010) as well as the avoidance behaviour of other subterranean termites species towards the location of borate-treated wood (Campora and Grace 2007). Termite monitoring stations should account for geographical location, since there are important features involved in this factor, such as termite species and population density, soil properties, alternative food sources or meteorological conditions that affect termite behaviour towards monitoring stations as well as monitoring stations effectiveness. Nevertheless, meteorological variables (E), which commonly are linked to spatial coordinates, showed weak effects after partialling out the effects of the other variables (spatial and matrix variables). These results may indicate that the meteorological data may be relative, although this could be misleading, since the measurement of temperature and relative humidity should probably be done in the monitoring station surroundings. Furthermore, the type of climate of the two monitoring areas is similar, since both belong to the temperate climate region.

Matrix was the most influential variable set within the monitoring station conditional variables, showing that matrix could be strategically chosen in order to obtain an effective monitoring station and bait. Effectively meaning that the matrix is (fungal) decay resistant and able to attract termites and allow their establishment ( $\mathrm{Su}$ et al. 2002, Cabrera and Thoms 2006, Evans and Gleeson 2006, Gautam and Henderson 2012). The presence of a rich cellulosic supply is important to increase the matrix consumption by termites, especially when alternative food sources are available (Lenz and Evans 2002, Lenz et al. 2009). In this study, H. brasiliensis was the preferred matrix, regardless of treatment applied, especially in Portugal, for $R$. grassei termites. The cellulosic matrix was offered in larger quantities to the termites, although Populus sp. matrix had a higher contact surface available for termites. H. brasiliensis was preferred by $R$. grassei over other wood species in previous laboratory testing (Grace et al. 1998, Wong and Grace 2004, Duarte et al. 2011). H. brasiliensis is considered to be susceptible to the attack of a wide variety of insects and fungi, including subterranean termites, due to its high content of starch, together with its low phenolic compounds content (Wong and Grace 2004, Teoh et al. 2011). In order to enable the utilization of this inexpensive and abundant tropical wood resource as a termite monitoring station matrix (Teoh et al. 2011), it would be interesting to profit 
from the attractive properties this wood has to subterranean termites, but it should be accomplished with an improvement of its resistance to other decay agents. For the cellulose powder matrix, no mass loss was registered, although some moulds were observed. Termites were detected only once (together with detection in the woody part - Populus sp. - of the monitoring station), suggesting that this matrix, although being resistant to other decay factors, may not optimize the opportunity for termite attack.

Borate was considered to be an effective termiticide in laboratory studies with termites, although some avoidance behaviour and the probable ability of termites to metabolize boron-treated wood may suggest the adjustment of control strategies based on the exposure of termites to boron compounds (Campora and Grace 2007, Gentz and Grace 2008). The borate treatments applied to H. brasiliensis did not show significant effects in this analysis, both in terms of termite repellence (termite visits were lessened) or decay resistance. Although Wong and Grace (2004) verified that borate treatments were effective for enhancing the resistance of $\mathrm{H}$. brasiliensis to a subterranean termite (Coptotermes formosanus Shiraki) attack, in laboratory conditions.

\section{CONCLUSIONS}

Though commercial baiting methods have been in place for over 20 years the performance of termite in-ground baiting / monitoring stations still has grounds to be improved namely through the optimization of its design and food matrix. For example, a durable matrix would be preferred for medium or long-term monitoring programs, in order to reduce disturbance and monitoring costs; cellulosic matrix contact area should be increased in order to attract termites to feed and install in that matrix; the selection of cellulosic matrix should be accordingly with the target termite species feeding preferences; termite feeding behaviour when different food sources are available is also an important data to account for. Termite ability to forage in and around the monitoring station is important for termite installation and cellulosic matrix consumption. This general advice should be evaluated through laboratory and field testing before termite monitoring station and bait system commercialization, bearing in mind that there are species- and location-specific variables which may influence the effectiveness of the termite in-ground monitoring stations. 


\section{REFERENCES}

Austin, J.; Szalanski, A.; Myles, T.; Borges, P.A.V.; Nunes, L.; Scheffrahn, R. 2012. First record of Reticulitermes flavipes (Isoptera: Rhinotermitidae) from Terceira Island (Azores, Portugal). Florida Entomologist 95(1): 196-198.

Bankhead-Dronnet, S.; Perdereau, E.; Kutnik, M.; Dupont, S.; Bagnères, A.G. 2015. Spatial structuring of the population genetics of a European subterranean termite species. Ecology and Evolution 5(15): 3090-3102.

Borcard, D.; Legendre, P.; Drapeau, P. 1992. Partialling out the spatial component of ecological variation. Ecology 73(3): 1045-1055.

Cabrera, B.; Thoms, E. 2006. Versatility of baits containing noviflumuron for control of structural infestations of Formosan subterranean termites (Isoptera: Rhinotermitidae). Florida Entomologist 89(1): 20-31.

Campora, C.; Grace, J.K. 2007. Behavioral response of the Formosan subterranean termite to borate-treated wood. Proceedings of the Hawaiian Entomological Society 39: 127-137.

Cornelius, M.; Osbrink, W. 2010. Effect of soil type and moisture availability on the foraging behavior of the Formosan subterranean termite. Journal of Economical Entomology 103(3): 799-807.

Cushman, S.A.; Wallin, D.O. 2002. Separating the effects of environmental, spatial and disturbance factors on forest community structure in the Russian Far East. Forest Ecology and Management 168: 201-215.

Duarte, S.; Ricart, M.; Nunes, L. 2011. Food preferences of Reticulitermes grassei (Clément) (Isoptera: Rhinotermitidae) in relation to different wood species (in Portuguese). Proceedings CIMAD11 - $1^{\circ}$ Congresso Ibero-LatinoAmericano da Madeira na Construção, 7-9 June 2011. Coimbra, Portugal.

Eger, J.E.Jr.; Hamm, R.L.; Demark, J.J.; Chin-Heady, E.; Tolley, M.P.; Benson, E.P; Zungoli, P.A.; Smith, M.S.; Spomer, N.A. 2014. Durability of a novel durable bait for control of subterranean termites (Isoptera: Rhinotermitidae): results of five-year field aging studies. Journal of Economical Entomology 107(3): 1201-1205.

Evans, T.; Gleeson, P. 2006. The effect of bait design on bait consumption in termites (Isoptera: Rhinotermitidae). Bulletin of Entomological Research 96: 85-90.

Evans, T.; Forschler, B.T.; Grace, J.K. 2012. Biology of invasive termites: A worldwide review. Annual Review of Entomology 58: 455-474.

Evans, T.; Iqbal, N. 2015. Termite (order Blattodea, infraorder Isoptera) baiting 20 years after commercial release. Pest Management Science 71(7): 897-906.

Gautam, B.; Henderson, G. 2012. Escape behavior of the Formosan subterranean termite (Isoptera: Rhinotermitidae) in response to disturbance. Journal of Insect Behavior 25: 70-79.

Gentz, M.; Grace, J.K. 2008. The response and recovery of the Formosan subterranean termite (Coptotermes formosanus Shiraki) from sublethal boron exposures. International Journal of Pest Management 55(1): 63-67.

Ghesini, S.; Pilon, N.; Marini, M. 2011. A new finding of Reticulitermes flavipes in northern Italy. Bulletin of Insectology 64 (1): 83-89.

Glenn, G.J.; Gold, R.E. 2002. Evaluation of commercial termite baiting systems for pest management of the Formosan subterranean termite (Isoptera: Rhinotermitidae). In Jones, S.C., J. Zhai and W.H. Robertson (eds.), Proceedings of the $4^{\text {th }}$ International Conference on Urban Pests, Charleston, North Carolina, USA. 
Grace, J.K.; Wong, A.; Tome, C. 1998. Termite resistance of Malaysian and exotic woods with plantation potential: Laboratory evaluation. $29^{\text {th }}$ Annual Meeting of the International Research Group on Wood Preservation, 14-19 June, Maastricht, Netherlands. IRG/WP 98-10280. 8 p.

Grand, J.; Cushman, S.A. 2004. A multi-scale analysis of species-environment relationships: Breeding birds in a pitch pine-scrub oak (Pinus rigida-Quercus ilicifolia) community. Biological Conservation 112(3): 307-317.

Legendre, P.; Legendre, L. 1998. Numerical ecology: developments in environmental modeling. $2^{\text {nd }}$ ed. Elsevier Science BV. Amsterdam, The Netherlands. 853 p.

Lenz, M.; Evans, T. 2002. Termite bait technology: perspectives from Australia (pp. 27-36). In Jones, S.C., J. Zhai and W.H. Robertson (eds.), Proceedings of the $4^{\text {th }}$ International Conference on Urban Pests, Charleston, North Carolina, USA.

Lenz, M.; Kard, B.; Evans, T.; Mauldin, J.; Etheridge, J.; Abbey, H. 2009. Differential use of identical food resources by Reticulitermes flavipes (Isoptera: Rhinotermitidae) in two types of habitats. Environmental Entomology 38(1): 35-42.

National Weather Service Forecast Office. 2012. [online] <http://w2.weather.gov/climate/index. php?wfo=mrx $>$ [accessed: 2012/03/02]

Nobre, T.; Nunes, L. 2007. Non-traditional approaches to subterranean termite control in buildings. Wood Material Science and Engineering 3-4: 147-156.

Nobre, T.; Nunes, L.; Eggleton, P.; Bignell, D. 2006. Distribution and genetic variation of Reticulitermes (Isoptera: Rhinotermitidae) in Portugal. Heredity 96: 403-409.

Ripa, R.; Luppichini, P.; Su, N.Y.; Rust, M. 2007. Field evaluation of potential control strategies against the invasive Eastern subterranean termite (Isoptera: Rhinotermitidae) in Chile. Journal of Economic Entomology 100(4): 1391-1399.

Rust, M.; Su, N.Y. 2012. Managing social insects of urban importance. Annual Review of Entomology 57: 355-375.

Su, N.Y.; Scheffrahn, R. 2000. Termites as pests of buildings. In Abe, T., D. Bignell and M. Higashi (eds.), Termites: Evolution, Sociality, Symbioses, Ecology (pp. 437-453). Kluwer Academic Publishers. Dordrecht, The Netherlands.

Su, N.-Y.; Ban, P.; Scheffrahn, R. 2002. Control of subterranean termite populations at San Cristóbal and El Morro, San Juan National Historic Site. Journal of Cultural Heritage 3: 217-225.

Taylor, A.M.; Kim, J.W.; Duarte, S.; Nunes, L.; Lloyd, J.D. 2010. Preventing decay in termite monitoring stations. $41^{\text {th }}$ Annual Meeting of the International Research Group on Wood Preservation, 9-13 May, Biarritz, France. IRG/WP 10-30546. 12 p.

Teoh, Y.; Don, M; Ujang, S. 2011. Assessment of the properties, utilization, and preservation of rubberwood (Hevea brasiliensis): a case study in Malaysia. Journal of Wood Science 57: 255-266.

Ter Braak, C.J.F.; Smilauer, P. 2002. CANOCO reference manual and CanoDraw for Windows user's guide: software for canonical community ordination (version 4.5). Microcomputer Power. Ithaca, NY, USA. 500 p.

Vargo, E.L. 2003. Genetic structure of Reticulitermes flavipes and $R$. virginicus (Isoptera: Rhinotermitidae) colonies in an urban habitat and tracking of colonies following treatment with hexaflumuron bait. Environmental Entomology 32(5): 1271-1282.

Verma, M.; Sharma, S.; Prasad, R. 2009. Biological alternatives for termite control: a review. International Biodeterioration and Biodegradation 63: 959-972. 
Weather underground, 2012. [online] http://www.wunderground.com/?MR=1 [accessed: 2012/03/02]

Wong, A.; Grace, J.K. 2004. Resistance of borate-treated rubberwood chipboard to the Formosan subterranean termite (Isoptera: Rhinotermitidae). Sociobiology 44 (3): 519-526.

Woodrow, R.; Shelton, T.; Oshiro, R.; Grace, J.K.; Wagner, T. 2008. Effects of disturbanceinduced trauma on foraging by subterranean termites (Isoptera: Rhinotermitidae). Sociobiology 52(1): 107-118. 